\title{
Implications of Lateral Cerebellum in Proactive Control of Saccades
}

\author{
Jun Kunimatsu, ${ }^{1,2}$ Tomoki W. Suzuki, ${ }^{1}$ and Masaki Tanaka ${ }^{1}$ \\ ${ }^{1}$ Department of Physiology, Hokkaido University School of Medicine, Sapporo 060-8638, Japan, and ${ }^{2}$ Laboratory of Sensorimotor Research, National Eye \\ Institute, National Institutes of Health, Bethesda, Maryland 20892
}

\begin{abstract}
Although several lines of evidence establish the involvement of the medial and vestibular parts of the cerebellum in the adaptive control of eye movements, the role of the lateral hemisphere of the cerebellum in eye movements remains unclear. Ascending projections from the lateral cerebellum to the frontal and parietal association cortices via the thalamus are consistent with a role of these pathways in higher-order oculomotor control. In support of this, previous functional imaging studies and recent analyses in subjects with cerebellar lesions have indicated a role for the lateral cerebellum in volitional eye movements such as anti-saccades. To elucidate the underlying mechanisms, we recorded from single neurons in the dentate nucleus of the cerebellum in monkeys performing anti-saccade/pro-saccade tasks. We found that neurons in the posterior part of the dentate nucleus showed higher firing rates during the preparation of antisaccades compared with pro-saccades. When the animals made erroneous saccades to the visual stimuli in the anti-saccade trials, the firing rate during the preparatory period decreased. Furthermore, local inactivation of the recording sites with muscimol moderately increased the proportion of error trials, while successful anti-saccades were more variable and often had shorter latency during inactivation. Thus, our results show that neuronal activity in the cerebellar dentate nucleus causally regulates anti-saccade performance. Neuronal signals from the lateral cerebellum to the frontal cortex might modulate the proactive control signals in the corticobasal ganglia circuitry that inhibit early reactive responses and possibly optimize the speed and accuracy of anti-saccades.
\end{abstract}

Key words: anti-saccade; cerebellum; dentate nucleus; inactivation; primate; single neurons

\section{Significance Statement}

Although the lateral cerebellum is interconnected with the cortical eye fields via the thalamus and the pons, its role in eye movements remains unclear. We found that neurons in the caudal part of the lateral (dentate) nucleus of the cerebellum showed the increased firing rate during the preparation of anti-saccades. Inactivation of the recording sites modestly elevated the rate of erroneous saccades to the visual stimuli in the anti-saccade trials, while successful anti-saccades during inactivation tended to have a shorter latency. Our data indicate that neuronal signals in the lateral cerebellum may proactively regulate anti-saccade generation through the pathways to the frontal cortex, and may inhibit early reactive responses and regulate the accuracy of anti-saccades.

\section{Introduction}

The roles of the cerebellum in movement control have been extensively examined in oculomotor systems. In particular, many

\footnotetext{
Received March 5, 2016; revised May 22, 2016; accepted May 25, 2016.

Author contributions: J.K. and M.T. designed research; J.K. and T.W.S. performed research; J.K. analyzed data; J.K. and M.T. wrote the paper.

This work was supported by grants from the Ministry of Education, Culture, Sports, Science and Technology of Japan; the Ministry of Health, Labour and Welfare of Japan; and the Takeda Science Foundation. We thank R. Takeya for participating in some recording experiments; T. Mori and A. Hironaka for their assistance with animal care, surgery, and histological work; and M. Suzuki for her administrative help. We also thank M. Takei and Y. Hirata in the Equipment Developing Group, Research Institute for Electronic Science, for manufacturing equipment.

The authors declare no competing financial interests.

Correspondence should be addressed to either Jun Kunimatsu or Masaki Tanaka, Department of Physiology, Hokkaido University School of Medicine, North 15, West 7, Sapporo 060-8638, Japan. E-mail: kunimatsu.jun@gmail.com or masaki@med.hokudai.ac.jp.
}

previous studies show that the floccular complex and the vermal lobules (V-VII and IX-X) of the cerebellar cortex regulate signals in the brainstem, playing an essential role in the adaptive control of eye movements (for review, see Nagao, 2004; Shadmehr and Krakauer, 2008; Lisberger, 2009; Iwamoto and Kaku, 2010; Kheradmand and Zee, 2011). However, how the lateral hemisphere of the cerebellar cortex is involved in eye movements remains largely unknown. Anatomically, the lateral (dentate) nucleus of the cerebellum receives signals from the hemispheres of the cerebellar cortex, and in turn sends outputs to the medial and lateral prefrontal cortex, the frontal eye field (FEF), and the

D01:10.1523/JNEUROSCI.0733-16.2016

Copyright $\odot 2016$ the authors $\quad 0270-6474 / 16 / 367066-09 \$ 15.00 / 0$ 
A
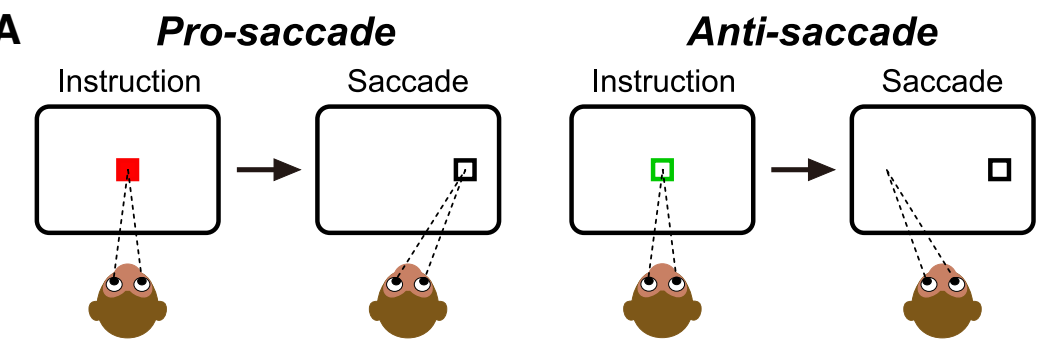

B
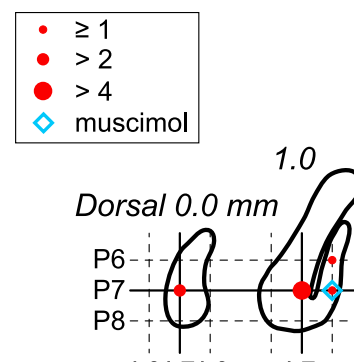

L'8L7Ĺ6

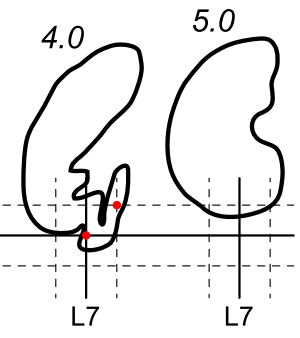

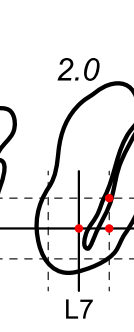

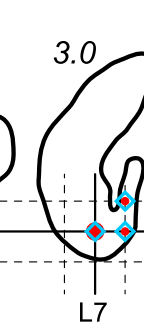

Figure 1. Behavioral tasks and locations of task-related neurons. $\boldsymbol{A}$, Trial type was indicated by the color of the FP. A white target spot appeared $16^{\circ}$ eccentrically at the time of the FP offset. Animals were required to make a saccade toward (pro-saccade) or away from (anti-saccade) the target within 350 or $400 \mathrm{~ms}$. B, Recording sites reconstructed from histological sections in monkey $\mathrm{G}$. Drawings of horizontal sections are arranged from the most dorsal to ventral portions of the dentate nucleus. The electrode penetrations were perpendicular to the drawings. Size of symbols indicates the number of task-related neurons recorded from each site. Blue diamonds indicate inactivation sites.

lateral intraparietal area via the thalamus (Lynch et al., 1994; Strick et al., 2009; Prevosto et al., 2010). In addition, previous studies showed that electrical stimulation applied to the lateral cerebellum elicited both saccadic and smooth eye movements (Ron and Robinson, 1973), and that neurons in the Crus I and II of the cerebellar hemisphere (Mano et al., 1991) displayed a burst of activity during saccades. More recently, Ashmore and Sommer (2013) showed that neurons in the dentate nucleus exhibited preparatory activity $\sim 600 \mathrm{~ms}$ before self-initiated saccades, indicating a role for the lateral cerebellum in oculomotor decisionmaking (for review, see Raghavan et al., 2016).

These previous observations indicate that the cerebellar hemisphere is involved in higher-order oculomotor control. Consistent with this, subjects with focal cerebellar lesions or degeneration showed deficits in visual search (Machner et al., 2005), response inhibition (Hübner et al., 2007), and the generation of sequential saccades (King et al., 2011; Filippopulos et al., 2013). Furthermore, recent studies in cerebellar patients have suggested a role for the cerebellum in anti-saccades (Hübner et al., 2007; Fielding et al., 2010; Peterburs et al., 2015). In contrast to innate, reactive saccade to the target, anti-saccade requires proactive control-the neural process to suppress inappropriate response and to maintain behavioral goals in anticipation of future events (Munoz and Everling, 2004; Braver, 2012). In support of the findings in patients, functional imaging studies in healthy individuals have repeatedly detected enhanced activity in the lateral cerebellum, in addition to the basal ganglia and the cortical eye fields, during antisaccades (Luna et al., 2001; Tu et al., 2006). Furthermore, some cerebellar Purkinje cells in the Crus I and II of nonhuman primates were reported to exhibit firing modulation before and after anti-saccades (Avila et al., 2013).

These previous observations prompted us to explore neuronal signals in the lateral cerebellum in monkeys performing antisaccades. We found that neurons in the caudal part of the cere- bellar dentate nucleus exhibited increased firing rate during anti-saccades compared with pro-saccades. Moreover, local pharmacological inactivation of these neurons moderately disrupted anti-saccade performance while pro-saccade performance remained unchanged. These results suggest that the lateral cerebellum may play a role in modulating the proactive, but not reactive, control signals for saccades that might be further processed in the corticobasal ganglia circuitry. Part of the present results have been reported in abstract form (Kunimatsu et al., 2014).

\section{Materials and Methods}

Animal preparation. Experiments were conducted in three Japanese monkeys (Macaca fuscata; weight range, $7-8 \mathrm{~kg}$; two females and one male). All experimental protocols were approved by the Hokkaido University Animal Care and Use Committee. The details of surgical procedures for implanting head holders, eye coil, and recording cylinder were described previously (Tanaka, 2005; Kunimatsu and Tanaka, 2010). All surgeries were performed using sterile procedures under general isoflurane anesthesia. Analgesic agents were administered during each surgery and during the following few days.

Visual stimuli and behavioral tasks. During training and experimental sessions, monkeys were seated quietly in a primate chair placed in a darkened booth. Visual stimuli were presented on a 24 inch cathode-ray tube monitor (refresh rate, $60 \mathrm{~Hz}$ ) that was located $38 \mathrm{~cm}$ away from their eyes and subtended $64 \times 44^{\circ}$ of visual angle. Our monkeys performed two tasks called the pro-saccade and anti-saccade tasks (Fig. 1). During the pro-saccade task, the monkey made a saccade to a visible target. During the anti-saccade task, the monkey made a saccade to a location that was the same distance as the visible target but in the opposite direction. In both tasks, the fixation point (FP; $0.5^{\circ}$ square spot) was initially gray for $800 \mathrm{~ms}$, and the animals were required to maintain eye position within $2^{\circ}$ of the FP. Then, the color of the FP was changed to red or green for $800 \mathrm{~ms}$ to inform monkeys of the trial type (the "instruction period"). In some experiments, the instruction period was either $2300 \mathrm{~ms}$ or a random $1300 \pm 1000 \mathrm{~ms}$ to promote erroneous saccades (see below). Monkeys were required to make pro-saccades in trials with a red FP, while they made anti-saccades in trials with a green FP. In both tasks, the FP was extinguished at the end of the instruction period, and the target was presented $16^{\circ}$ to the left or right of the FP. In the anti-saccade task, the target was relocated to the opposite side after 350 or $400 \mathrm{~ms}$ of its initial appearance. The animals were required to move their eyes to the "window" that surrounded the saccade goal within 350 or $400 \mathrm{~ms}$ following the FP offset. The size of the window was $6^{\circ}$ for anti-saccades and $3^{\circ}$ for pro-saccades. Correct performance was reinforced with a reward of a drop of liquid at the end of each trial.

Recording and inactivation procedures. To record from single neurons, a glass-coated tungsten electrode (Alpha Omega Engineering) was lowered into the dentate nucleus of the cerebellum through a 23 gauge guide tube using a micromanipulator (MO-97S; Narishige). The location of electrode penetration was adjusted using a grid system (Crist Instruments), and the guide tube was advanced $<2 \mathrm{~mm}$ below the surface of the cerebellar tentorium. We amplified and filtered $(0.3-10 \mathrm{kHz}$; Model 1800; A-M Systems) signals obtained from the electrodes, and listened to them on an audio speaker. Waveforms of action potentials from a single neuron were isolated using a real-time spike sorter with templatematching algorithms (ASD; Alpha Omega Engineering). We searched for task-related neurons when monkeys performed a block of randomized 
anti-saccade/pro-saccade trials with an instruction period of $800 \mathrm{~ms}$. For many neurons, the instruction period was prolonged during recording sessions so that the animals made more erroneous saccades in the antisaccade trials. During recording sessions, we initially selected neurons with saccade-related firing rate changes by monitoring sounds from the audio device, and then attempted to isolate single neurons. Thus, because neurons were preselected on-line, we were unable to report the exact proportion of saccade-related neurons among all recorded neurons in the dentate nuclei. Typically, only three to five neurons in each penetration exhibited clear saccade-related firing modulation.

For the inactivation experiments, we manufactured an injectrode consisting of an epoxy-coated tungsten microelectrode (FHC Inc.) and a 50 $\mathrm{cm}$ silica tube (inner diameter, $40 \mu \mathrm{m}$; Polymicro Technology). The silica tube was connected to a $10 \mu \mathrm{l}$ Hamilton microsyringe that was set to a micropump (NanoJet; Chemyx) for the remote drug infusion. We inserted the injectrode through the guide tube and recorded single or multiunit activity. Then a small amount of $\mathrm{GABA}_{\mathrm{A}}$ agonist (muscimol; 5 $\mu \mathrm{g} / \mu \mathrm{l}$ dissolved in saline) was pressure injected using the micropump around the sites where the task-related neurons were previously recorded ( $1 \mu \mathrm{l}$ in volume for two sites along the penetration, $>500 \mu \mathrm{m}$ apart). Previous studies estimated that the spread of $1 \mu \mathrm{l}$ muscimol in the brain tissue was $\sim 1.0$ to $2.0 \mathrm{~mm}$ in radius (Partsalis et al., 1995; Arikan et al., 2002; Goodkin and Thach, 2003). The inactivation effects were assessed by comparing eye movements before and 15-90 min after muscimol infusion. We also injected saline as a control in separate experiments to ensure that the effect was not caused by a volume effect.

Histological procedures. Recording sites in monkey G were reconstructed from the histological sections. At the end of the experiments, several electrolytic lesions were made at or near the sites where the taskrelated neurons were recorded. Lesions were made by passing a direct current through the recording electrodes $(10-20 \mu \mathrm{A}$, tip negative) for $30-40 \mathrm{~s}$. The animal was then deeply anesthetized with sodium pentobarbital (60 mg/kg, i.p.) and perfused with $0.1 \mathrm{M}$ phosphate buffer followed by $3.5 \%$ formalin. The brain was cut into transverse sections at $50 \mu \mathrm{m}$ thicknesses using a freezing microtome, and each section was stained with cresyl violet. We reconstructed the location of each taskrelated neuron according to the depth and the coordinates of electrode penetrations, and the relative locations of the marking lesions.

Data acquisition and analyses. We measured the neuronal activity during the following three time periods: (1) the $300 \mathrm{~ms}$ interval immediately before the instruction (baseline period); (2) the $400 \mathrm{~ms}$ interval starting from $300 \mathrm{~ms}$ before target onset (instruction period); and (3) the $100 \mathrm{~ms}$ interval before saccade initiation (saccade period). We defined neurons as task related when they showed different firing rates among the three measuring intervals according to one-way ANOVA, and when post hoc multiple comparisons (Scheffés method) detected a significant difference in activity during the baseline or other periods in either task $(p<0.05)$. The time course of neuronal activity for each condition was qualitatively examined by constructing the spike density function using a Gaussian kernel ( $\sigma=15 \mathrm{~ms})$.

For the inactivation experiment, we computed the rate of error trials before and after muscimol injection for each condition. The error rates were computed only for trials in which monkeys maintained fixation until the FP disappeared, and the rate of error trials was evaluated before and during inactivation ( $\chi^{2}$ test). Saccade latency was defined as the time from target onset to the time of saccade initiation. Saccade accuracy was quantified by measuring the distance between the saccade endpoint and the location of the visual stimulus. For the analyses of saccade latency and accuracy, we included data from error trials in which saccades landed within $8^{\circ}$ of the correct locations.

\section{Results}

In monkeys performing the anti-saccade/pro-saccade tasks, we searched for neurons in the posterior part of the cerebellar dentate nucleus (Fig. $1 B$ ) that discharged before saccades. Among 64 dentate neurons examined formally, 53 exhibited a significant firing modulation during either or both of the instruction and the saccade periods (Materials and Methods; $n=25,24$, and 4, re- spectively, for monkeys $\mathrm{G}, \mathrm{B}$, and X). More than half neurons $(53 \%, 28$ of 53$)$ were located within the ventral $60 \%$ of the dentate nucleus in each electrode penetration, while this proportion differed among animals (57\%, 46\%, and 50\% for monkeys G, B, and $\mathrm{X}$, respectively). Since we did not find a clear difference in neuronal activity between the ventral and dorsal groups, the data were combined for the analyses.

\section{Comparison of task-related activity between paradigms}

Figure $2 A$ shows a representative neuron exhibiting a greater activity for anti-saccades than pro-saccades. To quantify the modulation of the preparatory activity for individual neurons, we measured the firing rates during a $400 \mathrm{~ms}$ interval starting from $300 \mathrm{~ms}$ before the FP offset (Fig. 2A, black bar). Because the saccade target appeared at the time of the FP offset, no directional information was available for monkeys during the instruction period. We therefore combined the data for trials in both directions. Among 53 neurons, 40 neurons (75\%) exhibited different firing rates in the baseline and the instructional periods $(p<$ 0.05, multiple comparisons with Scheffé's method). Of these, 31 neurons $(58 \%)$ displayed significantly different firing rates during the instructional period (preparatory activity) for prosaccades and anti-saccades (Wilcoxon rank-sum test, $p<0.05$; Fig. $2 B$, filled circles). For the population as a whole, the preparatory activity during anti-saccade trials was significantly greater than that during the pro-saccade trials (paired $t$ test, $p<0.001$ ). The time courses of the population activity plotted in Figure $2 C$ show that the task-dependent firing modulation emerged $\sim 400$ ms following the instruction and was evident at the time of target onset. Some neurons showed a significant correlation between the average firing rate during the preparatory period and saccade latencies $(n=10,14,11$, and 10, of 53 neurons for ipsiversive pro-saccades, anti-saccades, contraversive pro-saccades, antisaccades, respectively; $p<0.05$ ); however, the regression slopes derived from individual neurons in any condition did not differ from zero in the population (one-sample $t$ test, $p>0.3$ ).

To compare neural activity just before saccade initiation between the tasks, the firing rates were also measured during a 100 ms interval before saccades (Fig. $2 E$, black bar). Figure $2 D$ plots the firing rates for anti-saccades as a function of those for prosaccades in ipsilateral (circle) and contralateral (triangle) directions. Among 53 neurons, 20 (38\%) neurons displayed different firing rates between tasks for ipsiversive saccades, while 23 neurons $(43 \%)$ displayed different firing for contraversive saccades (Wilcoxon rank-sum test, $p<0.05$; Fig. $2 D$, filled symbols). The population activity was statistically different during anti-saccades compared with during pro-saccades in both directions (paired $t$ test, $p<0.001$ ). The time courses of population activity (Fig. $2 E$ ) also demonstrated that firing rates during anti-saccades were higher than during pro-saccades. However, these neurons exhibited no directional bias in both paradigms (unpaired $t$ test, $p=$ 0.61 and 0.48 , respectively, for pro-saccade and anti-saccade). Two-way ANOVA for the population of neurons detected a significant effect of saccade paradigm $(p<0.05)$ but no directional modulation $(p=0.40)$ or interaction between them $(p=0.85)$. Thus, neurons in the dentate nucleus showed increased firing rates during anti-saccades regardless of saccade direction.

\section{Neuronal activity in error trials}

Monkeys sometime made erroneous saccades to the visual stimuli in the anti-saccade task. To examine neuronal activity in these error trials, we introduced the two saccade tasks with a longer instruction period ( $2300 \mathrm{~ms}$ or random $1300 \pm 1000 \mathrm{~ms})$ in two 
A

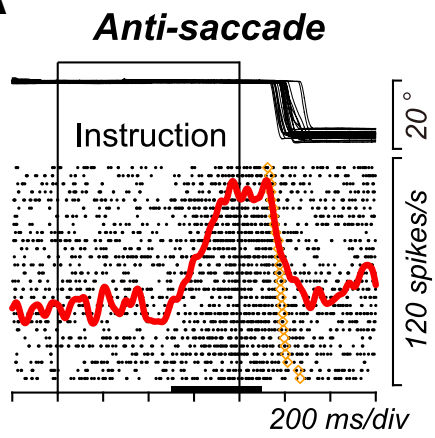

Pro-saccade

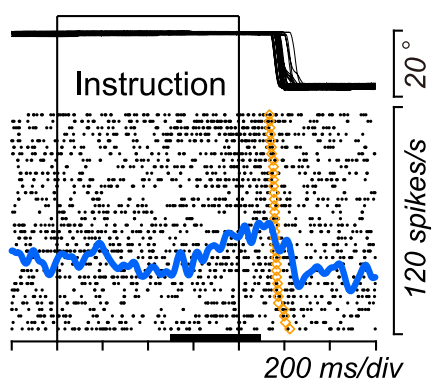

B

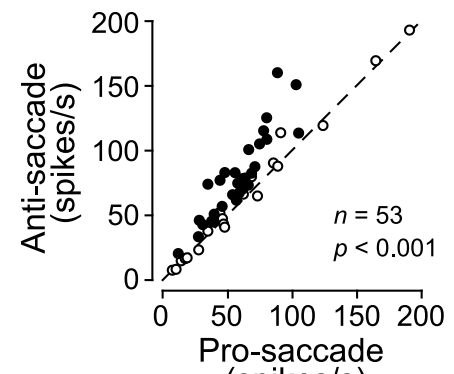

(spikes/s)

D

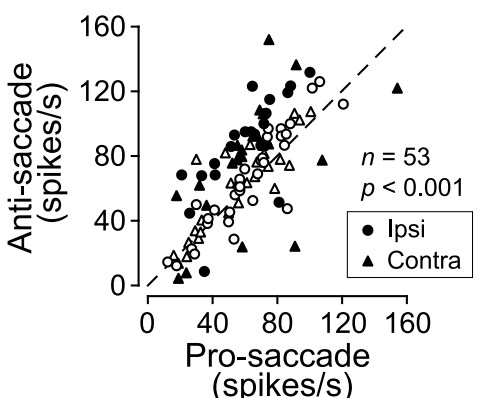

C

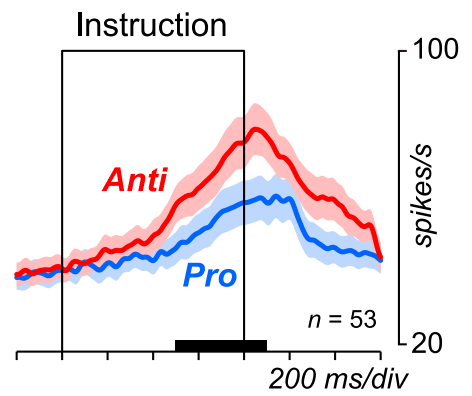

E

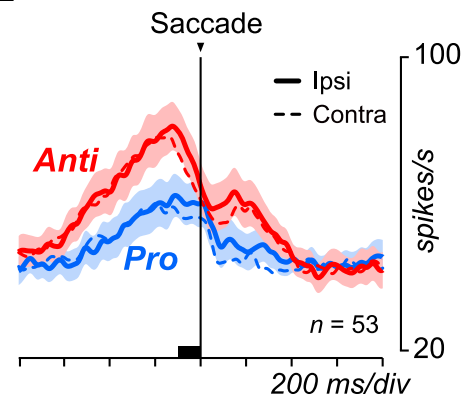

Figure 2. Neuronal activity in the dentatenucleus during anti-saccade(Anti)/pro-saccade(Pro)tasks. A, A representativeneuron showing differentfiring rate during the tasks. Color of theFPdiffered between the tasks during the $800 \mathrm{~ms}$ period delimited by two vertical lines. The yellow symbol on each raster line indicates the time of saccade. $\boldsymbol{B}$, Each data point compares the firing rate of individual neurons during anti-saccades with that during pro-saccades. Neuronal activity was measured for a $400 \mathrm{~ms}$ interval starting from $300 \mathrm{~ms}$ before the FP offset (black bars in $A$ and $C$ ). To examine the activity during the instruction period, data for saccades in both directions were combined. Filled symbols indicate the data showing a significant difference (Wilcoxon rank sum test, $p<0.05$ ). C, Time courses of the population activity during the instruction period. The shaded areas indicate $\pm S E M$. D, Activities around the time of saccades were compared between anti-saccade trials and pro-saccade trials. The firing rate was measured for a $100 \mathrm{~ms}$ interval before saccades (black bar in $\boldsymbol{E}$ ). Circles and triangles indicate ipsiversive (Ipsi) and contraversive (Contra) saccades, respectively. E, Time courses of the population activity aligned with saccade initiation. Solid and dashed traces indicate the data for ipsiversive and contraversive saccades, respectively. The shaded areas indicate \pm SEM of the data for ipsiversive saccades. div, Division.

A

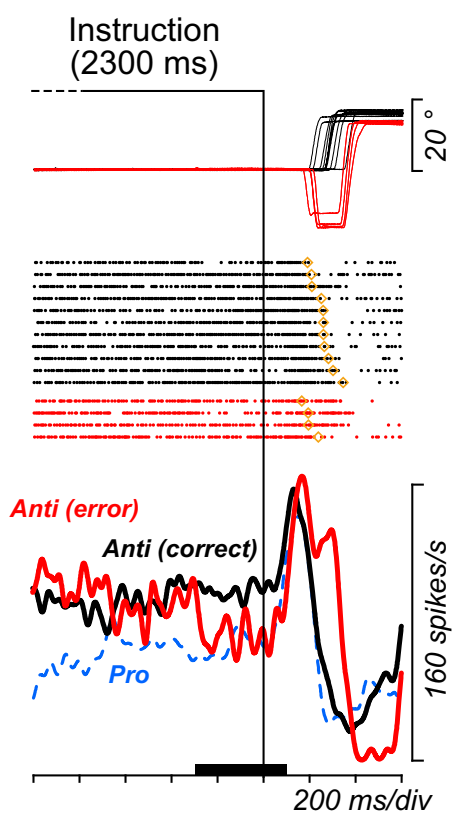

B

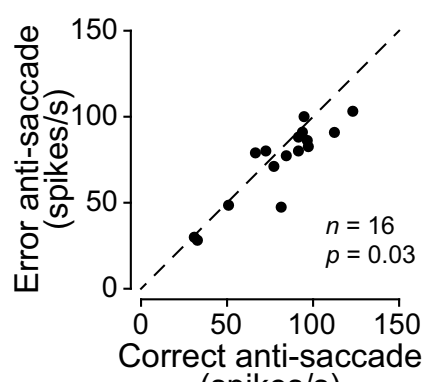

(spikes/s)

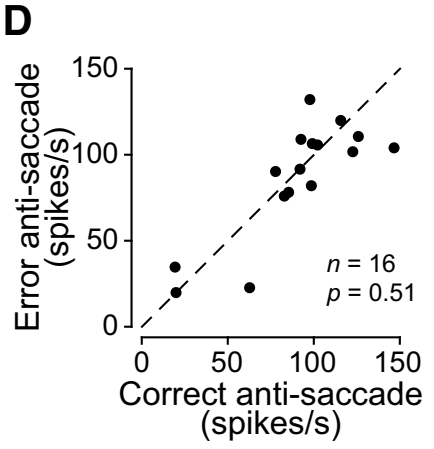

C

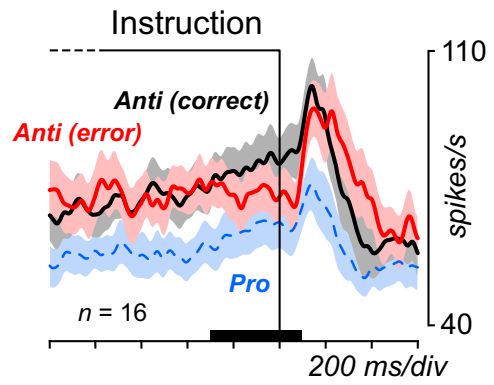

$\mathbf{E}$

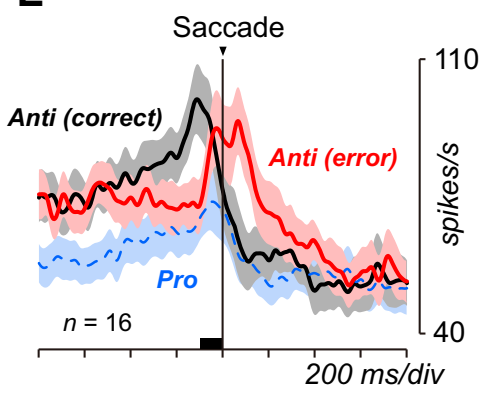

Figure 3. Analysis of neuronal activity in error trials. A, Activity of a single dentate neuron during correct and erroneous anti-saccade trials. Black traces and rasters indicate correct trials, while red traces and rasters indicate error trials. Blue broken trace on the bottom panel indicates the data for correct pro-saccades (Pro). B, Each data point compares the firing rate of individual neurons during correct anti-saccades (Anti) trials with that during erroneous anti-saccade trials. Neuronal activity was measured for a $400 \mathrm{~ms}$ interval starting from $300 \mathrm{~ms}$ before the FP offset (black bars in $A$ and $C$ ). Data for both saccade directions were combined. $C$, Time courses of the population activity for correct anti-saccade, erroneous anti-saccade, and correct pro-saccade trials. The shaded areas indicate \pm SEM. D. Activities around the time of saccades were compared between correct and erroneous anti-saccade trials. The firing rate was measured for a $100 \mathrm{~ms}$ interval before saccades (black bar in $\boldsymbol{E}$ ). $\boldsymbol{E}$, Time courses of the population activity aligned on saccade initiation. The shaded areas indicate \pm SEM. div, Division. 
monkeys ( $G$ and $B)$. In these trials, monkeys made erroneous saccades more frequently in the anti-saccade task. Neuronal activity was examined when the animals maintained fixation until the FP offset; neuronal activity in trials with early fixation break was not further considered. Figure $3 A$ shows data from a representative neuron. Firing rates at the end of the instruction period in erroneous anti-saccade trials (red traces) were lower than those in successful anti-saccade trials (black traces). To quantify modulation in individual neurons, we measured firing rates during the instruction period (Fig. $3 A$, black bar). For this analysis, data for both saccade directions were combined, and neurons were included only when neuronal activity was examined for more than three error trials. For the population of 16 neurons (Fig. 3B), the preparatory activity during erroneous anti-saccade trials was significantly lower than that during correct anti-saccade trials (paired $t$ test, $p=0.03$ ). The time courses of the population activity plotted in Figure $3 \mathrm{C}$ also show a difference in firing rate at the end of the instruction period. However, neuronal activity just before erroneous pro-saccades was similar to that before antisaccades (Fig. $3 D$; paired $t$ test, $p=0.51$ ), while the timing of transient activity relative to saccade initiation was clearly different between the correct and erroneous trials (Fig. 3E). Neuronal activity just before erroneous pro-saccades was greater than that before correct pro-saccades (paired $t$ test, $p=0.03$ ).

\section{Effects of local inactivation}

To explore the causal role of neuronal activity, the recording sites were reversibly inactivated by injecting a small amount of muscimol ( $5 \mu \mathrm{g} / \mu \mathrm{l} ; 1 \mu \mathrm{l}$ for two sites along the penetration) in three monkeys. The drug was injected unilaterally in each experiment. Figure $4 A$ shows the traces of eye position before and during inactivation. Although the monkey performed the tasks perfectly before inactivation, it generated many erroneous saccades toward the contralateral target in anti-saccade trials during inactivation (36\%; $\chi^{2}$ test, $\left.p<0.01\right)$. In error trials, the animal made a saccade away from the target even before the target was relocated to the correct anti-saccade goal (Fig. $4 A$, open triangle). Figure $4 B$ summarizes the changes in error rate following muscimol injection. Among 11 experiments, 7 exhibited significant changes in error rate for anti-saccades ( 3 ipsiversive, 2 contraversive, 2 bidirectional deficits), but none showed a significant change for prosaccades. Injections of saline $(2 \mu \mathrm{l})$ into five effective sites failed to alter error rates in either task (changes in error rate ranged from -4.6 to $9.0 \%$; mean $\pm \mathrm{SD}, 1.2 \pm 3.3 \%$ ), indicating that the effects of muscimol injection were not attributed to a volume effect. Although inactivation of the cerebellum significantly altered anti-saccade performance, the inactivation effect was smaller than that observed previously during thalamic inactivation (twoway ANOVA, $p<0.001$; Kunimatsu and Tanaka, 2010).

We also found that inactivation of the dentate nucleus altered the reaction time and accuracy of anti-saccades. Figure $5 \mathrm{~A}$ compares the reaction time (top panels) and accuracy (bottom panels) of successful trials before and during inactivation. Inactivation of the dentate nucleus shortened the latency (paired $t$ test, $p=0.03)$ and worsened the accuracy $(p=0.04)$ of contraversive anti-saccades (Fig. $5 A$, top panels, red dots), while both the latency and accuracy of ipsiversive anti-saccades as well as those of pro-saccades (Fig. $5 A$, blue crosses) in both directions remained unchanged. Furthermore, changes in the latency and accuracy of contraversive but not ipsiversive anti-saccades correlated with each other (Fig. 5B; Pearson's $r=-0.66$ and 0.35 , respectively, for contraversive and ipsiversive saccades). Inactivation did not alter saccade velocity, acceleration, and duration, or
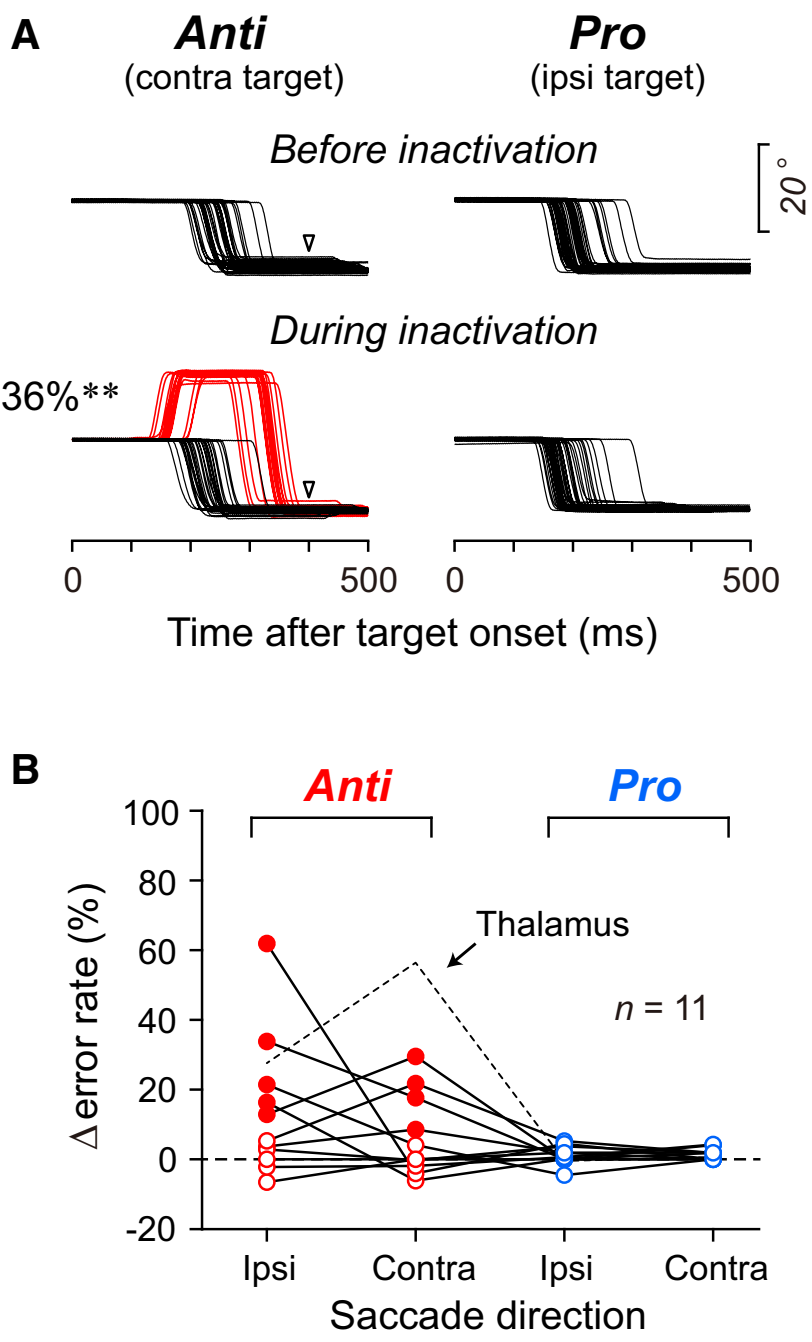

Figure 4. Inactivation effects on the rate of error trials. $\boldsymbol{A}$, Traces of eye position before and during inactivation of the left dentate nucleus. Data are aligned with the target onset. Red traces indicate error trials. The open triangles indicate the time of target relocation in the anti-saccade (Anti) task. Note that the animal redirected her eyes to the goal immediately following erroneous pro-saccades (Pro). $\boldsymbol{B}$, Changes in error rate for all injection experiments. Filled symbols indicate the data showing a significant difference ( $\chi^{2}$ test, $p<0.01$ ). Dashed lines indicate the means of the data of the previous inactivation experiments performed in the oculomotor thalamus (Kunimatsu and Tanaka, 2010). Ipsi, Ipsilateral; Contra, contralateral.

the coefficient of variation of latencies in any condition, except for contraversive anti-saccade deceleration (paired $t$ test, $p=$ 0.04; Table 1). These results suggest that inactivation of the dentate nucleus in our experiments did not alter neuronal activity in the oculomotor-related regions in the interposed and the fastigial nuclei that directly control saccade dynamics (Robinson and Fuchs, 2001; Iwamoto and Kaku, 2010).

\section{Discussion}

In this study, we found that neurons in the cerebellar dentate nucleus showed increased firing rate during the preparation of anti-saccades. This activity was attenuated in error trials, while the same neurons exhibited a transient activity around the time of erroneous pro-saccades (Fig. 3). Furthermore, inactivation of the recording sites increased the occurrence of erroneous prosaccades in the anti-saccade trials, and altered the latency and accuracy of successful anti-saccades but not pro-saccades. Thus, to the best of our knowledge, the present study provides 
A - Contralateral -
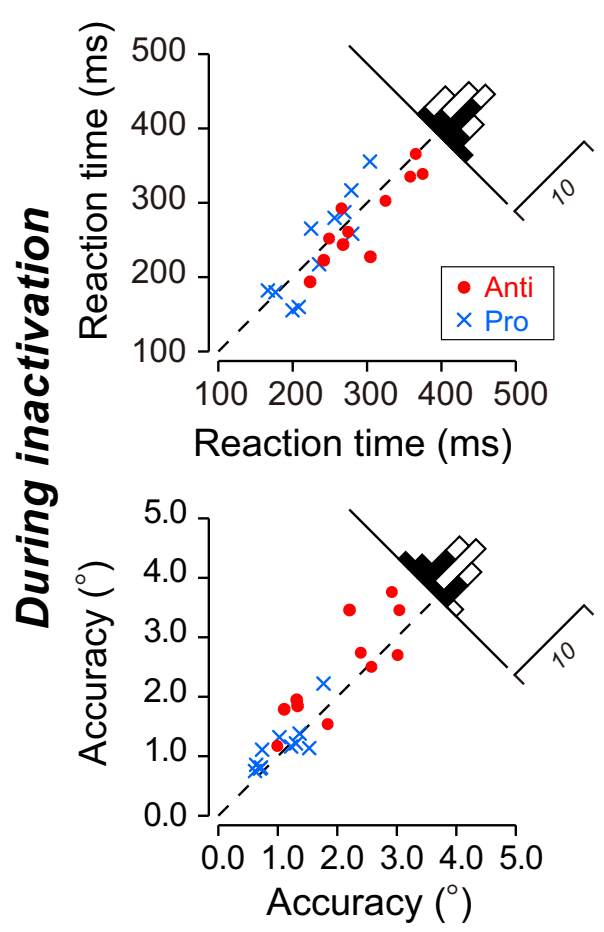

\section{Before inactivation}

B

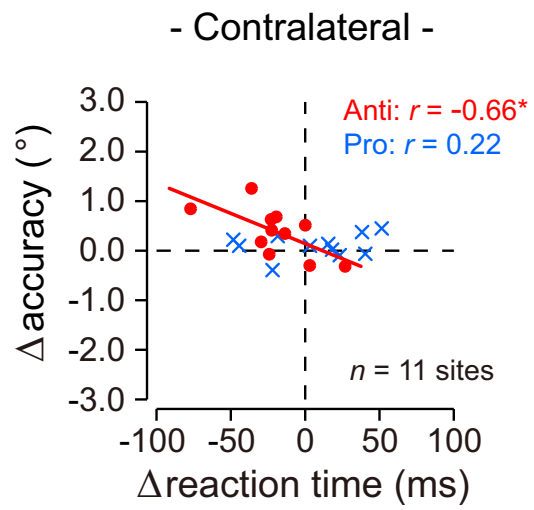

- Ipsilateral -
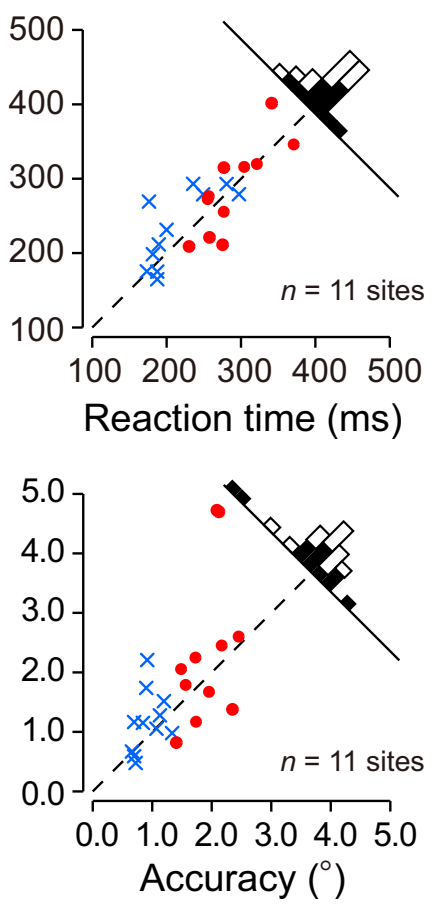

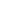


and that global and specific inhibition might be regulated by different basal ganglia pathways (for review, see Aron, 2011; Jahanshahi et al., 2015; Yoshida and Tanaka, 2016). Because response inhibition also requires an intact cerebellum (Brunamonti et al., 2014), the increased error rate and reduced anti-saccade latency during inactivation of the dentate nucleus might result from the impairment of proactive control.

We also found that the reduction of anti-saccade latency during inactivation often accompanied the increased variation of anti-saccade endpoints (Fig. $5 B$ ). This was in contrast to a previous finding in the basal ganglia where inactivation of the globus pallidus increased the directional error but did not alter the latency or accuracy of anti-saccades (Yoshida and Tanaka, 2009). Optimizing the speed and accuracy of movements is another strategy of deliberate motor control, and its neuronal correlates in the cerebral cortex were recently investigated (Heitz and Schall, 2012; Hanks et al., 2014). Because the cerebellum is essential for accurate movements, signals from the lateral cerebellum to the frontal cortex might mediate the trade-off between latency and accuracy of anti-saccades.

For deliberate control, error detection and behavioral adjustment compose a key functional element (Jocham and Ullsperger, 2009). The cerebello-thalamo-cortical pathways are thought to play a role in error detection in the stop-signal reaction time task (Ide and Li, 2011; Zhang and Li, 2012). For anti-saccades, recent studies showed that error-related scalp potentials just after erroneous pro-saccades were significantly reduced in subjects with focal cerebellar lesions (Peterburs et al., 2013) and that the magnitude of the cortical potentials correlated with the gray matter volume of the lateral cerebellum in patients with cerebellar degeneration (Peterburs et al., 2015). In the present study, we found a strong transient activity around the times of erroneous prosaccades, but a similar amount of activity was also found well before correct anti-saccades (Fig. 3D,E). The time courses of neuronal activity indicated that the transient activity might be related to the sudden appearance of saccade target rather than the occurrence of erroneous saccades (Fig. 3D). Although these neuronal activities are likely to be reduced in patients with cerebellar diseases, the difference in experimental conditions makes it difficult to further consider a possible relationship between neuronal activity and error-related potentials reported previously. Exploring the cortical potentials in animals before and during inactivation of the dentate nucleus would provide a critical test in future studies.

\section{Relation to the previous studies in the basal ganglia and the thalamus}

Figure $6 \mathrm{~A}$ compares the time courses of neuronal activity around the time of saccades among the cerebellum, the oculomotor thalamus, and the basal ganglia (globus pallidus) taken from previous studies in our laboratory (Kunimatsu and Tanaka, 2010; Yoshida and Tanaka, 2016). Neurons in all these areas exhibited greater activity for anti-saccades than pro-saccades. Activity in the cerebellar dentate nucleus started earliest, peaked well before saccade initiation, and declined abruptly during saccades. These results were consistent with the notion that signals from the lateral cerebellum might regulate saccade planning through pathways to the prefrontal cortex. For neurons previously recorded from the ventrolateral, ventroanterior, and intralaminar nuclei of the thalamus, the data were divided according to the presence or absence of the instruction period activity (Fig. 5C; Kunimatsu and Tanaka, 2010, their Fig. 8A). Neurons without a significant instruction period activity displayed a brisk burst of activity that
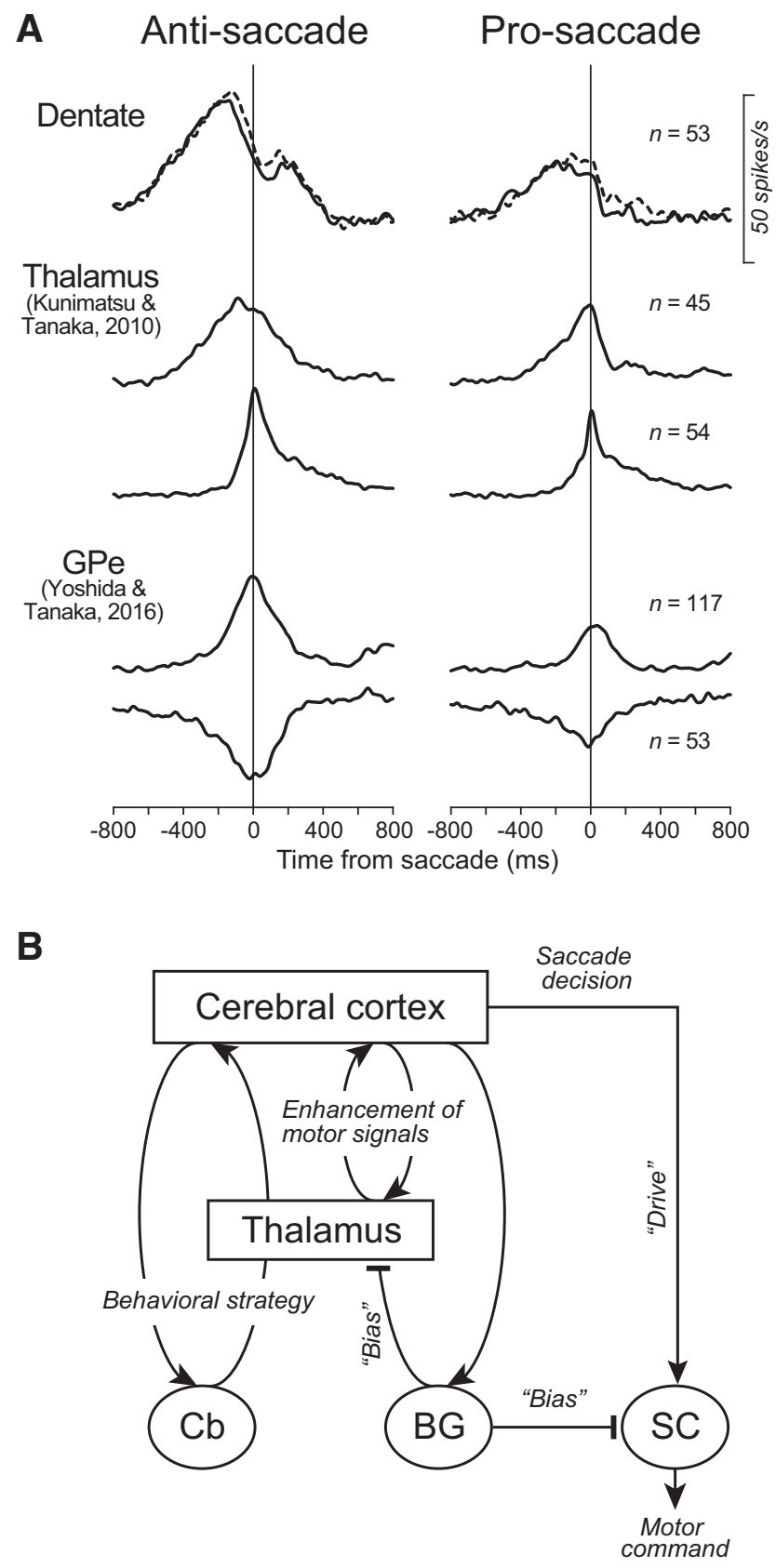

Figure 6. $\boldsymbol{A}$, Comparison of the time courses of the population activity for neurons in the dentate nucleus, oculomotor thalamus, and the globus pallidus externus (GPe). Data for antisaccades/pro-saccades are shown separately in different columns. On each column, the top traces plot the population activity shown in Figure $2 E$. For neurons previously recorded from the ventrolateral, ventroanterior, and intralaminar nuclei of the thalamus (Kunimatsu and Tanaka, 2010), the data are separately plotted for neurons with or without the instruction period activity. For neurons in the GPe (Yoshida and Tanaka, 2016), the data are shown for those exhibiting the increased or decreased activity during saccades. For the cerebellum, solid and dashed traces indicate the data for ipsiversive and contraversive saccades, respectively. For the other brain regions, the data for contraversive saccades only are shown. $\boldsymbol{B}$, A hypothetical diagram of neural mechanism for the generation of anti-saccades. BG, Basal ganglia; $\mathrm{Cb}$, cerebellum; SC, superior colliculus.

peaked around the time of saccades, similarly to neurons in the FEF (Everling and Munoz, 2000) and the SEF (Schlag-Rey et al., 1997; Amador et al., 2004), suggesting a possible role in the generation of movement signals. In contrast, thalamic neurons with a significant instruction period activity showed a similar time course of activity to neurons in the cerebellum. Neurons in the 
basal ganglia also exhibited a strong preparatory activity but maximal firing modulation often followed saccade initiation (Ford and Everling, 2009; Watanabe and Munoz, 2009; Yoshida and Tanaka, 2009). These results suggest that preparatory activity in the thalamus may reflect signals from the cerebellum or the basal ganglia, while the saccade-related transient activity might reflect inputs from the cerebral cortex or the brainstem (Goldberg et al., 2013).

Figure $6 B$ shows a hypothetical diagram of neural processing for anti-saccades. In this diagram, the thalamus enhances motor signals through the local circuitry with the frontal cortex. It has been shown that the basal ganglia-recipient thalamic nuclei receive strong feedback from the cerebral cortex (Yamawaki and Shepherd, 2015). In addition, the thalamus also relays signals from the lateral cerebellum to the prefrontal cortex to modulate the proactive signals. The basal ganglia may regulate the gain of transmission in the thalamus and the superior colliculus through their inhibitory projections. It is important to note that Figure $6 B$ is highly speculative. Nevertheless, the dual functional roles of the oculomotor thalamus might account for the fact that inactivation of the thalamus exhibited a severe anti-saccade deficit with both increased error rate and deterioration of anti-saccade parameters (Kunimatsu and Tanaka, 2010), while inactivation of the cerebellar nucleus caused a relatively mild anti-saccade deficit (Fig. 4). This diagram might also fit data showing that inactivation of the globus pallidus increased erroneous pro-saccades but did not alter the latency or accuracy of anti-saccades (Yoshida and Tanaka, 2009). Signals arising from the lateral cerebellum might regulate the preparatory signals for anti-saccades that have been reported in the lateral prefrontal cortex (Johnston and Everling, 2006) and/or the SEF (Amador et al., 2004). To verify these hypotheses, the time courses of neuronal activity in different areas in the frontal cortices, thalamus and basal ganglia need to be explored. Furthermore, either the on-line electrophysiological testing of connections of the task-related neurons in the network, or the pathway-specific manipulation of incoming signals during single neuronal recordings using pharmacological, optogenetic, or cryogenic inactivation techniques in future studies would greatly help us to understand these processes.

\section{References}

Abegg M, Sharma N, Barton JJ (2012) Antisaccades generate two types of saccadic inhibition. Biol Psychol 89:191-194. CrossRef Medline

Amador N, Schlag-Rey M, Schlag J (2004) Primate antisaccade. II. Supplementary eye field neuronal activity predicts correct performance. J Neurophysiol 91:1672-1689. CrossRef Medline

Arikan R, Blake NM, Erinjeri JP, Woolsey TA, Giraud L, Highstein SM (2002) A method to measure the effective spread of focally injected muscimol into the central nervous system with electrophysiology and light microscopy. J Neurosci Methods 118:51-57.

Aron AR (2011) From reactive to proactive and selective control: developing a richer model for stopping inappropriate responses. Biol Psychiatry 69:e55-68. CrossRef Medline

Ashmore RC, Sommer MA (2013) Delay activity of saccade-related neurons in the caudal dentate nucleus of the macaque cerebellum. J Neurophysiol 109:2129-2144. CrossRef Medline

Avila E, Godschalk M, Roelfsema P, van der Togt C, Holland P, Thier P, Frens MA, De Zeeuw CI (2013) Pro- and antisaccade Purkinje cell activity in oculomotor vermis and lateral cerebellum. Soc Neurosci Abstr 39:647.03.

Bellebaum C, Daum I, Suchan B (2012) Mechanisms of cerebellar contributions to cognition in humans. Wiley Interdiscip Rev Cogn Sci 3:171-184. CrossRef Medline

Boxer AL, Garbutt S, Rankin KP, Hellmuth J, Neuhaus J, Miller BL, Lisberger SG (2006) Medial versus lateral frontal lobe contributions to voluntary saccade control as revealed by the study of patients with frontal lobe degeneration. J Neurosci 26:6354-6363. CrossRef Medline
Braver TS (2012) The variable nature of cognitive control: a dual mechanisms framework. Trends Cogn Sci 16:106-113. CrossRef Medline

Brunamonti E, Chiricozzi FR, Clausi S, Olivito G, Giusti MA, Molinari M, Ferraina S, Leggio M (2014) Cerebellar damage impairs executive control and monitoring of movement generation. PLoS One 9:e85997. CrossRef Medline

Chen X, Scangos KW, Stuphorn V (2010) Supplementary motor area exerts proactive and reactive control of arm movements. J Neurosci 30:1465714675. CrossRef Medline

Condy C, Wattiez N, Rivaud-Péchoux S, Tremblay L, Gaymard B (2007) Antisaccade deficit after inactivation of the principal sulcus in monkeys. Cereb Cortex 17:221-229. CrossRef Medline

Dum RP, Strick PL (2003) An unfolded map of the cerebellar dentate nucleus and its projections to the cerebral cortex. J Neurophysiol 89:634-649.

Everling S, Munoz DP (2000) Neuronal correlates for preparatory set associated with pro-saccades and anti-saccades in the primate frontal eye field. J Neurosci 20:387-400. Medline

Fielding J, Corben L, Cremer P, Millist L, White O, Delatycki M (2010) Disruption to higher order processes in Friedreich ataxia. Neuropsychologia 48:235-242. CrossRef Medline

Filippopulos F, Eggert T, Straube A (2013) Effects of cerebellar infarcts on cortical processing of saccades. J Neurol 260:805-814. CrossRef Medline

Ford KA, Everling S (2009) Neural activity in primate caudate nucleus associated with pro- and antisaccades. J Neurophysiol 102:2334-2341. CrossRef Medline

Frank MJ, Samanta J, Moustafa AA, Sherman SJ (2007) Hold your horses: impulsivity, deep brain stimulation, and medication in parkinsonism. Science 318:1309-1312. CrossRef Medline

Goldberg JH, Farries MA, Fee MS (2013) Basal ganglia output to the thalamus: still a paradox. Trends Neurosci 36:695-705. CrossRef Medline

Goodkin HP, Thach WT (2003) Cerebellar control of constrained and unconstrained movements. I. Nuclear inactivation. J Neurophysiol 89: 884-895. CrossRef Medline

Hanks T, Kiani R, Shadlen MN (2014) A neural mechanism of speedaccuracy tradeoff in macaque area LIP. Elife 3:e02260. CrossRef Medline

Heitz RP, Schall JD (2012) Neural mechanisms of speed-accuracy tradeoff. Neuron 76:616-628. CrossRef Medline

Hoover JE, Strick PL (1999) The organization of cerebellar and basal ganglia outputs to primary motor cortex as revealed by retrograde transneuronal transport of herpes simplex virus type 1. J Neurosci 19:1446-1463.

Hübner J, Sprenger A, Klein C, Hagenah J, Rambold H, Zühlke C, Kömpf D, Rolfs A, Kimmig H, Helmchen C (2007) Eye movement abnormalities in spinocerebellar ataxia type 17 (SCA17). Neurology 69:1160-1168. CrossRef Medline

Ide JS, Li CS (2011) A cerebellar thalamic cortical circuit for error-related cognitive control. Neuroimage 54:455-464. CrossRef Medline

Isoda M, Hikosaka O (2008) Role for subthalamic nucleus neurons in switching from automatic to controlled eye movement. J Neurosci 28: 7209-7218. CrossRef Medline

Ito M (2002) The molecular organization of cerebellar long-term depression. Nat Rev Neurosci 3:896-902. CrossRef Medline

Iwamoto Y, Kaku Y (2010) Saccade adaptation as a model of learning in voluntary movements. Exp Brain Res 204:145-162. CrossRef Medline

Jahanshahi M, Obeso I, Rothwell JC, Obeso JA (2015) A fronto-striatosubthalamic-pallidal network for goal-directed and habitual inhibition. Nat Rev Neurosci 16:719-732. CrossRef Medline

Jocham G, Ullsperger M (2009) Neuropharmacology of performance monitoring. Neurosci Biobehav Rev 33:48-60. CrossRef Medline

Johnston K, Everling S (2006) Monkey dorsolateral prefrontal cortex sends task-selective signals directly to the superior colliculus. J Neurosci 26: 12471-12478. CrossRef Medline

Kheradmand A, Zee DS (2011) Cerebellum and ocular motor control. Front Neurol 2:53. CrossRef Medline

King S, Chen AL, Joshi A, Serra A, Leigh RJ (2011) Effects of cerebellar disease on sequences of rapid eye movements. Vision Res 51:1064-1074. CrossRef Medline

Kunimatsu J, Tanaka M (2010) Roles of the primate motor thalamus in the generation of antisaccades. J Neurosci 30:5108-5117. CrossRef Medline

Kunimatsu J, Suzuki T, Tanaka M (2014) Contribution of the cerebellar dentate nucleus to the generation of anti-saccades. Soc Neurosci Abstr 40:62.04. 
Leiner HC, Leiner AL, Dow RS (1986) Does the cerebellum contribute to mental skills? Behav Neurosci 100:443-454. CrossRef Medline

Lisberger SG (2009) Internal models of eye movement in the floccular complex of the monkey cerebellum. Neuroscience 162:763-776. CrossRef Medline

Lu X, Miyachi S, Takada M (2012) Anatomical evidence for the involvement of medial cerebellar output from the interpositus nuclei in cognitive functions. Proc Natl Acad Sci U S A 109:18980-18984. CrossRef Medline

Luna B, Thulborn KR, Munoz DP, Merriam EP, Garver KE, Minshew NJ, Keshavan MS, Genovese CR, Eddy WF, Sweeney JA (2001) Maturation of widely distributed brain function subserves cognitive development. Neuroimage 13:786-793. CrossRef Medline

Lynch JC, Hoover JE, Strick PL (1994) Input to the primate frontal eye field from the substantia nigra, superior colliculus, and dentate nucleus demonstrated by transneuronal transport. Exp Brain Res 100:181-186. Medline

Machner B, Sprenger A, Kömpf D, Heide W (2005) Cerebellar infarction affects visual search. Neuroreport 16:1507-1511. CrossRef Medline

Mano N, Ito Y, Shibutani H (1991) Saccade-related Purkinje cells in the cerebellar hemispheres of the monkey. Exp Brain Res 84:465-470. Medline

Miall RC (1998) The cerebellum, predictive control and motor coordination. Novartis Found Symp 218:272-284. Medline

Munoz DP, Everling S (2004) Look away: the anti-saccade task and the voluntary control of eye movement. Nat Rev Neurosci 5:218-228. CrossRef Medline

Nagao S (2004) Pontine nuclei-mediated cerebello-cerebral interactions and its functional role. Cerebellum 3:11-15. CrossRef Medline

Partsalis AM, Zhang Y, Highstein SM (1995) Dorsal Y group in the squirrel monkey: II. Contribution of the cerebellar flocculus to neuronal responses in normal and adapted animals. J Neurophysiol. 73:632-650.

Peterburs J, Koch B, Schwarz M, Hoffmann KP, Daum I, Bellebaum C (2013) Cortical processing of saccade-related efference copy signals in patients with cerebellar lesion. Eur J Neurosci 37:804-815. CrossRef Medline

Peterburs J, Thürling M, Rustemeier M, Göricke S, Suchan B, Timmann D, Bellebaum C (2015) A cerebellar role in performance monitoring- evidence from EEG and voxel-based morphometry in patients with cerebellar degenerative disease. Neuropsychologia 68:139-147. CrossRef Medline

Prevosto V, Graf W, Ugolini G (2010) Cerebellar inputs to intraparietal cortex areas LIP and MIP: functional frameworks for adaptive control of eye movements, reaching, and arm/eye/head movement coordination. Cereb Cortex 20:214-228. CrossRef Medline
Raghavan RT, Prevosto V, Sommer MA (2016) Contribution of cerebellar loops to action timing. Curr Opin Behav Sci 8:28-34. CrossRef

Ramnani N (2006) The primate cortico-cerebellar system: anatomy and function. Nat Rev Neurosci 7:511-522. CrossRef Medline

Robinson FR, Fuchs AF (2001) The role of the cerebellum in voluntary eye movements. Annu Rev Neurosci 24:981-1004. CrossRef Medline

Ron S, Robinson DA (1973) Eye movements evoked by cerebellar stimulation in the alert monkey. J Neurophysiol 36:1004-1022. Medline

Schlag-Rey M, Amador N, Sanchez H, Schlag J (1997) Antisaccade performance predicted by neuronal activity in the supplementary eye field. Nature 390:398-401. CrossRef Medline

Shadmehr R, Krakauer JW (2008) A computational neuroanatomy for motor control. Exp Brain Res 185:359-381.

Stoodley CJ, Valera EM, Schmahmann JD (2012) Functional topography of the cerebellum for motor and cognitive tasks: an fMRI study. Neuroimage 59:1560-1570. CrossRef Medline

Strick PL, Dum RP, Fiez JA (2009) Cerebellum and nonmotor function. Annu Rev Neurosci 32:413-434. CrossRef Medline

Tanaka M (2005) Involvement of the central thalamus in the control of smooth pursuit eye movements. J Neurosci 25:5866-5876. CrossRef Medline

Thach WT, Goodkin HP, Keating JG (1992) The cerebellum and the adaptive coordination of movement. Annu Rev Neurosci 15:403-442. CrossRef Medline

Tu PC, Yang TH, Kuo WJ, Hsieh JC, Su TP (2006) Neural correlates of antisaccade deficits in schizophrenia, an fMRI study. J Psychiatr Res 40: 606-612. CrossRef Medline

Watanabe M, Munoz DP (2009) Neural correlates of conflict resolution between automatic and volitional actions by basal ganglia. Eur J Neurosci 30:2165-2176. CrossRef Medline

Yamawaki N, Shepherd GM (2015) Synaptic circuit organization of motor corticothalamic neurons. J Neurosci 35:2293-2307. CrossRef Medline

Yoshida A, Tanaka M (2009) Enhanced modulation of neuronal activity during antisaccades in the primate globus pallidus. Cereb Cortex 19: 206-217. CrossRef Medline

Yoshida A, Tanaka M (2016) Two types of neurons in the primate globus pallidus external segment play distinct roles in antisaccade generation. Cereb Cortex 26:1187-1199. CrossRef Medline

Zhang S, Li CS (2012) Functional networks for cognitive control in a stop signal task: independent component analysis. Hum Brain Mapp 33: 89-104. CrossRef Medline 